
\title{
$\begin{array}{ll}\text { Research Square } & \begin{array}{l}\text { Preprints are preliminary reports that have not undergone peer review. } \\ \text { They should not be considered conclusive, used to inform clinical practice, } \\ \text { or referenced by the media as validated information. }\end{array}\end{array}$
}

\section{Local dry vitrectomy combined with segmental scleral buckling for the management of rhegmatogenous retinal detachment with vitreous traction}

Ping Fei

Xinhua Hospital, affiliated to Shanghai Jiaotong University School of Medicine https://orcid.org/0000-0001-7276-4630

Haiying Jin

Shanghai Tenth People's Hospital

Qi Zhang

Shanghai Jiaotong University School of Medicine Xinhua Hospital

Jie Peng

Shanghai Jiaotong University School of Medicine Xinhua Hospital

Jiakai Li

Shanghai Jiaotong University School of Medicine Xinhua Hospital

Jiao Lv

Shanghai Jiaotong University School of Medicine Xinhua Hospital

Tian Tian

Shanghai Jiaotong University School of Medicine Xinhua Hospital

Zupeng Lu

Shanghai Jiaotong University School of Medicine Xinhua Hospital

Peiquan Zhao ( $\sim$ zhaopeiquan@126.com )

Xinhua Hospital, affiliated to Shanghai Jiaotong University School of Medicine

Research article

Keywords: Dry vitrectomy; minimal invasion; retinal detachment; scleral buckling

Posted Date: June 17th, 2019

DOI: https://doi.org/10.21203/rs.2.10323/v1

License: (c) (1) This work is licensed under a Creative Commons Attribution 4.0 International License. Read Full License 


\section{Abstract}

Purpose: To demonstrate combined local dry vitrectomy and segmental scleral buckling for the treatment of partial rhegmatogenous retinal detachment (RRD) with local vitreous traction in patients at high-risk for proliferative vitreoretinopathy (PVR). Methods: Seven eyes of 7 patients were retrospectively studied, including 3 retinal dialysis, 3 retinal detachment (RD) with peripheral retinal holes and 1 RD with giant tear. All patients exhibited local vitreous traction and a high risk for PVR. Dry local vitrectomy without regular infusion was performed to remove the vitreous traction. Viscoelastic fluid was injected into the vitreous cavity if needed. Segmental scleral buckling was performed accordingly. Demographic information, preoperative and postoperative complications, and outcomes were recorded. Results: The mean age of the patients at presentation was $22.43 \pm 14.28$ years old. All seven patients obtained retinal reattachment after a single surgical intervention. Postoperative visual acuity was improved in all patients. None of them developed complications, except for temporary mildly increased intraocular pressure in 2 cases. Conclusions: Combined local dry vitrectomy and segmental scleral buckling is effective for patients of RRD with local vitreous traction. The technique avoids many complications associated with regular surgery and was minimally invasive to both the external and internal eye.

\section{Background}

Rhegmatogenous retinal detachment (RRD) can be surgically treated using scleral buckling, and/or pars plana vitrectomy (PPV). In patients at high risk for proliferative vitreoretinopathy (PVR) with RRD caused by vitreous traction, performing segmental scleral buckling alone poses a significant surgical challenge because persistent vitreous traction may lead to failure of the surgery[1]. However, regular vitrectomy has some potential complications, such as cataract, especially in young patients. Vitrectomy surgery may result in more diffuse vitreous-base disruption if the vitreous base is shaved over the peripheral retina and pars plana during aggressive vitreous removal[2]. The objective of this article is to introduce a modified technique that combines local dry vitrectomy (without regular infusion) and segmental scleral buckling, and to demonstrate the applicability of managing RRD with local vitreous traction in patients at high risk for PVR, especially young patients not suitable for regular vitrectomy.

\section{Methods}

\section{Patients and Methods}

Institutional review board approval was obtained for this retrospective review. The indications for this combined surgery were partial rhegmatogenous retinal detachment with local vitreous traction around the retinal hole or tear with preoperative PVR B. No one had posterior vitreous detachment (PVD) preoperatively. The following situations would be considered but not mandatory when making the decision, such as young age, macula-on status, good preoperative visual acuity of the operated eye and poor visual acuity of the fellow eye. All surgeries were performed by one surgeon (P.Z.). All patients underwent a comprehensive ophthalmic examination before surgical intervention, including clinical history, review of systems, measurement of best-corrected visual acuity (BCVA) and intraocular pressure (IOP), fundus photography, B scan, slit-lamp, and indirect biomicroscopy. The informed consent was obtained from all participants or his/her legal guardians if under 18 years.

\section{Surgical Technique}

1. Conjunctival incision for segmental scleral buckling was made according to the range and location of the retinal breaks. If the retinal hole was small, minimal in situ radial conjunctival incision ( 5 to $6 \mathrm{~mm}$ ) would be made [3]. If the retinal break or dialysis was extensive, the conjunctiva would be dissected at the limbus accordingly. Transconjunctival traction sutures were placed under the rectus muscles.

2. Local dry vitrectomy. 3-port (or 2-port) sclerotomies were made 3.5-4mm from the limbus. Dry local vitrectomy without regular liquid infusion by 23 -gauge vitreous cutter was performed to remove the vitreous traction and trim the margin around the retinal break under a noncontact wide-angle viewing system, or under microscopy directly with scleral depression if the retinal tear was in the periphery, such as retinal dialysis. Viscoelastic fluid was injected into the vitreous cavity to maintain intraocular pressure (IOP) if needed through one of the ports during the operation.

3. Segmental scleral buckling. After cryopexy, mark the precise location of the retinal break. One or two explants (silicone/silicone sponge) were placed according to the extent of the break. Suture the Tenon's capsule and the conjunctiva.

The combined procedures were demonstrated in the video (see Video, Supplemental Digital Content 1 and 2, which demonstrates the key steps of Case 1 and 2).

\section{Results}

All seven eyes of seven patients who underwent combined local dry vitrectomy and segmental scleral buckling by a single surgeon were included in this series: 3 retinal dialysis; 1 giant tear retinal detachment (RD); and 3 RDs with peripheral retinal holes. All patients exhibited local dense vitreous traction and a high risk for PVR.

Five of the patients were male and two were female. The mean ( $\pm S D)$ age at presentation was $22.43 \pm 14.28$ years old (range 7-45 years), including four teenagers. All patients exhibited partial RD. Five patients were macula-on at the time of surgery, with visual acuity of 20/40 or better, and two patients were macula-off, with visual acuity of $20 / 1000$ and $20 / 300$. All patients were followed for at least 6 months. The average follow-up duration was $22.14 \pm 11.61$ months (range 8-43 months). 
All seven patients obtained retinal reattachment after a single surgical intervention. Postoperative visual acuity was improved in all patients, including $20 / 20$ in 3 eyes and 20/25 in 2 eyes, which were preoperative macula-on cases. No patients developed intraoperative and postoperative complications, except temporary mildly increased IOP in the first to second week postoperatively in 2 cases (Table1, Fig 1-3).

\section{Discussion}

Surgical approaches for low-to-moderate complexity RDs have been well studied [1,4,5]. The most common cause of surgical failure in RRD is PVR. However, less is known about surgical outcomes in patients at high risk for PVR. This study presented a new technique involving combined local dry vitrectomy and segmental scleral buckling in RRD patients with local vitreous traction and a high risk for PVR.

Scleral buckling is an ophthalmic surgical technique that has been successfully used to repair RRDs for over 60 years. Scleral buckling has an important role in the repair of certain categories of RRDs. These include detachments in young phakic patients, detachments associated with dialysis, and also in conjunction with vitrectomy in patients who sustain trauma or have developed PVR [6]. However, in patients of RRD with vitreous traction, who are also at high risk for PVR, performing segmental scleral buckling alone poses a significant surgical challenge because persistent vitreous traction may lead to failure of the surgery. For patients at high risk for PVR, PPV-scleral buckling has been associated with significantly higher rates of anatomical success compared with PPV alone [1].

Combining local dry vitrectomy and segmental scleral buckling were performed in these eyes. Regular vitrectomy was not chosen because all cases in the present study were partial RD, including five macula-on cases. The patients were young, and four were younger than 18 years old. Two teenage patients' fellow eye had poor visual acuity $(\mathrm{FC} / 40 \mathrm{~cm}$ [case 3] and $\mathrm{FC} / 10 \mathrm{~cm}$ [case 7]) with a history of RD. The minimal interference of the vitreous cavity may lead to better prognosis, especially in young patients.

It has been established that vitrectomy is a risk factor for complicated cataract surgery and IOL dislocation. The main cause for nuclear cataracts after vitrectomy most probably is oxidative stress. Oxygen in the avascular lens is provided by diffusion, meaning that the surrounding oxygen content is crucial for the oxygen content within the lens. The partial oxygen pressure is highly elevated in the vitreous cavity after vitrectomy and posterior to the lens since the vitreous is lacking as a diffusion barrier for the oxygen. The partial oxygen pressure might be additionally elevated by ventilation with oxygen and a high oxygen pressure in the infusion fluid during surgery. This elevated partial oxygen pressure may lead to increased oxygen stress and thus to lens opacification by oxidation of structural proteins [7]. The key for the prevention of cataract formation therefore seems to be avoidance of oxidative stress. Local dry vitrectomy only removes the vitreous limited to the vitreous traction around retinal hole, tear or retinal dialysis without fluid infusion, which may reduce the oxidative stress of the lens and lead to less postoperative cataract formation.

Our case series demonstrates that this technique was highly effective for addressing these cases. The indications for this combined surgery were partial rhegmatogenous retinal detachment with local vitreous traction around the retinal hole or tear with preoperative PVR B plus. The following situations would be considered but not mandatory when making the decision, such as young age, macula-on status and good preoperative visual acuity. All seven eyes of seven patients in our case series (100\%) achieved anatomical success with a single surgical intervention. Postoperative visual acuity was improved in all patients, and five preoperative macula-on cases have maintained a better visual acuity of $20 / 25$. It is also a good method of finding hidden retinal holes with a light probe under microscopy. In case 1, a small retinal hole was found under microscopy, which was hidden beneath the vitreous traction.

The technique was also very safe. None of the cases experienced significant surgical complications intraoperatively or postoperatively. The entire procedure involves minimal surgical injury. The benefits of minimally invasive scleral buckling were well addressed in a previously published study [3]. Local limited dry vitrectomy can relieve vitreous traction with minimal disturbance of the vitreous cavity and carries less risk for PVR. Local dry vitrectomy can avoid the potential negative effect of intraocular infusion solutions on the retina [8]. None of our patients has experienced a complicated postoperative cataract, which has a high incidence in patients after regular vitrectomy [2]. This is especially important in young patients.

However, two patients exhibited mildly increased IOP one to two weeks postoperatively (cases 3 and 4), which returned to normal two to three weeks after the operation. When performing dry vitrectomy, viscoelastic solution was injected to maintain IOP instead of the regular infusion to avoid overly disturbing the vitreous. The reason for the temporarily increased IOP may be due to the migration of the viscoelastic solution from the vitreous cavity into the anterior chamber via the fragile zonule. The IOP may return to normal after the absorbance of viscoelastic solution.

Limitations of this study include a relatively small sample size and its retrospective design. Moreover, this was only a single surgeon's experience and, therefore, the results may not be universally applicable. A larger prospective cohort study involving multiple surgeons would be needed to assess the true success and complication rates of this technique.

In summary, combined local dry vitrectomy and segmental scleral buckling was a highly successful method of managing RRD with local vitreous traction in patients at high risk for PVR, especially in young patients. Careful preoperative and intraoperative planning should be undertaken to achieve minimal invasiveness and the best postoperative visual results.

\section{Abbreviations}

PPV: pars plana vitrectomy

BCVA: best corrected visual acuity

FC: finger count 
HM: high myopia

IOP: intraocular pressure

PHPV: persistent hyperplastic primary vitreous

RD: retinal detachment

RRD: rhegmatogenous retinal detachment

RRD: rhegmatogenous retinal detachment

PVR: proliferative vitreoretinopathy

\section{Declarations}

Ethics approval and consent to participate: This study was approved by Ethics Committee of Xin Hua Hospital affiliated to Shanghai Jiao Tong University School of Medicine. All procedures performed in studies involving human participants were in accordance with the ethical standards of the institutional and/or national research committee and with the 1964 Helsinki Declaration and its later amendments or comparable ethical standards. Informed consent was obtained from all individual participants included in the study. Consent for publication: Informed consent was obtained from all individual participants to publish the study. Availability of data and material: The datasets analyzed during the current study available from the corresponding author on request.

Competing interests: None

Funding: This research was supported by the National Natural Science Foundation Project of China (81500725, 81770963(P. F.), 81770964 (P. Z.)), Shanghai Shen Kang Hospital Development Center Program (16CR4017A), Program for Shanghai Outstanding Academic Leader (P.Z).

Authors' contributions: Design and conduct of the study (PZ); collection, analysis and interpretation of data (PF, HJ, QZ, JP, JL, JL, TT, ZL); preparation of manuscript(PF); critical review and final approval of the manuscript (PZ).

Acknowledgments: We sincerely thank all the patients and the patients and their families for their participation.

\section{References}

1. Alexander P, Ang A, Poulson A, Snead MP. Scleral buckling combined with vitrectomy for the management of rhegmatogenous retinal detachment associated with inferior retinal breaks. Eye (Lond). 2008;22(2):200-3.

2. Fenberg MJ, Hainsworth KJ, Rieger FG, 3rd, Hainsworth DP. Vitrectomy as a Risk Factor for Complicated Cataract Surgery. Missouri medicine. 2016;113(1):44-7.

3. Jin H, Zhang Q, Zhao P. Minimal in situ conjunctival incision for segmental scleral buckling surgery. Ophthalmic surgery, lasers \& imaging retina. 2014;45(6):574-6.

4. Bonnet M. The development of severe proliferative vitreoretinopathy after retinal detachment surgery. Grade B: a determining risk factor. Graefes Arch Clin Exp Ophthalmol. 1988;226(3):201-5.

5. Eibenberger K, Georgopoulos M, Rezar-Dreindl S, Schmidt-Erfurth U, Sacu S. Development of Surgical Management in Primary Rhegmatogenous Retinal Detachment Treatment from 2009 to 2015. Curr Eye Res. 2018;43(4):517-25.

6. Papakostas TD, Vavvas D. Postoperative Complications of Scleral Buckling. Semin Ophthalmol. 2018;33(1):70-4.

7. Petermeier K, Szurman P, Bartz-Schmidt UK, Gekeler F. Pathophysiology of cataract formation after vitrectomy. Klin Monbl Augenheilkd. 2010 Mar;227(3):175-80.

8. AbdEl Dayem H, Hartzer M, Williams G, et al. The Effect of Vitrectomy Infusion Solutions on Postoperative Electroretinography and Retina Histology. BMJ open ophthalmology 2017;1(1):e000004.

\section{Tables}

Table 1 Clinical characteristics of rhegmatogenous retinal detachment patients who underwent combined dry vitrectomy and segmental scleral buckling 


\begin{tabular}{|c|c|c|c|c|c|c|c|c|c|c|c|c|c|}
\hline Case & Age & Eye & Diagnosis & $\begin{array}{c}\text { Pre- } \\
\text { operative } \\
\text { BCVA }\end{array}$ & $\mathrm{RD}$ & $\begin{array}{c}\text { Retinal } \\
\text { Break }\end{array}$ & $\begin{array}{c}\text { Preoperative } \\
\text { PVR }\end{array}$ & $\begin{array}{l}\text { Vitreous } \\
\text { Traction }\end{array}$ & MacularStatus & $\begin{array}{c}\text { History of Ocular } \\
\text { Surgery }\end{array}$ & $\begin{array}{l}\text { Post- } \\
\text { operative } \\
\text { BCVA }\end{array}$ & $\begin{array}{l}\text { Postoperative } \\
\text { Complications }\end{array}$ & $\begin{array}{c}\text { Postoperative } \\
\text { Retinal } \\
\text { Status }\end{array}$ \\
\hline 1 & 7 & OD & $\begin{array}{l}\text { RRD, } \\
\text { PHPV }\end{array}$ & $20 / 25$ & $\begin{array}{c}9 \\
\text { o'clock }\end{array}$ & $\begin{array}{l}\text { retinal } \\
\text { hole, } \\
\text { temporal }\end{array}$ & $\mathrm{C}$ & + & on & - & $20 / 20$ & - & attached \\
\hline 2 & 17 & Os & RRD & $20 / 1000$ & $\begin{array}{c}4 \text { to } 7 \\
\text { o'clock }\end{array}$ & $\begin{array}{l}\text { dialysis } \\
\text { of ora } \\
\text { serrata, } \\
\text { temporal } \\
\text { inferior }\end{array}$ & B & + & off & - & $20 / 300$ & - & attached \\
\hline 3 & 13 & OD & RRD, HM & $20 / 25$ & $\begin{array}{c}5: 30 \text { to } \\
8 \\
\text { o'clock }\end{array}$ & $\begin{array}{l}\text { dialysis } \\
\text { of ora } \\
\text { serrata, } \\
\text { temporal } \\
\text { inferior }\end{array}$ & B & + & on & $\begin{array}{r}\text { fellow eye } \\
\text { vitrectomy+ } \\
\text { silicone oil }\end{array}$ & $20 / 25$ & $\begin{array}{l}\text { temporarily } \\
\text { mild } \\
\text { increased IOP }\end{array}$ & attached \\
\hline 4 & 45 & OD & $\mathrm{RRD}, \mathrm{HM}$ & $20 / 30$ & $\begin{array}{l}11 \text { to } 1 \\
\text { o'clock }\end{array}$ & $\begin{array}{l}\text { retinal } \\
\text { hole, } \\
\text { superior }\end{array}$ & B & + & on & $\begin{array}{c}\text { failure of } \\
\text { photocoagulation }\end{array}$ & $20 / 20$ & $\begin{array}{c}\text { temporarily } \\
\text { mild } \\
\text { increased IOP }\end{array}$ & attached \\
\hline 5 & 38 & OS & RRD & $20 / 300$ & $\begin{array}{c}3 \text { to } 6 \\
\text { o'clock }\end{array}$ & $\begin{array}{l}\text { giant } \\
\text { break, } \\
\text { temporal } \\
\text { inferior }\end{array}$ & B & + & off & - & $20 / 200$ & - & attached \\
\hline 6 & 25 & OD & RRD & $20 / 30$ & $\begin{array}{l}12 \text { to } 2 \\
\text { o'clock }\end{array}$ & $\begin{array}{l}\text { dialysis } \\
\text { of ora } \\
\text { serrata, } \\
\text { superior }\end{array}$ & B & + & on & 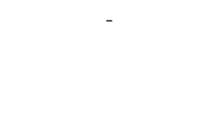 & $20 / 20$ & - & attached \\
\hline 7 & 12 & OD & RRD & $20 / 40$ & $\begin{array}{l}11 \text { to } 4 \\
\text { o'clock }\end{array}$ & $\begin{array}{l}\text { retinal } \\
\text { hole, } \\
\text { temporal }\end{array}$ & $\mathrm{C}$ & + & on & $\begin{array}{l}\text { fellow eye } \\
\text { vitrectomy+ } \\
\text { silicon oil }\end{array}$ & $20 / 20$ & - & attached \\
\hline
\end{tabular}

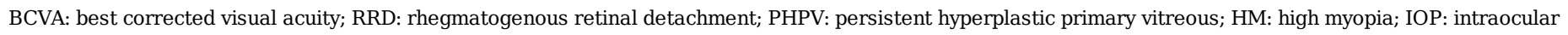
pressure

\section{Figures}



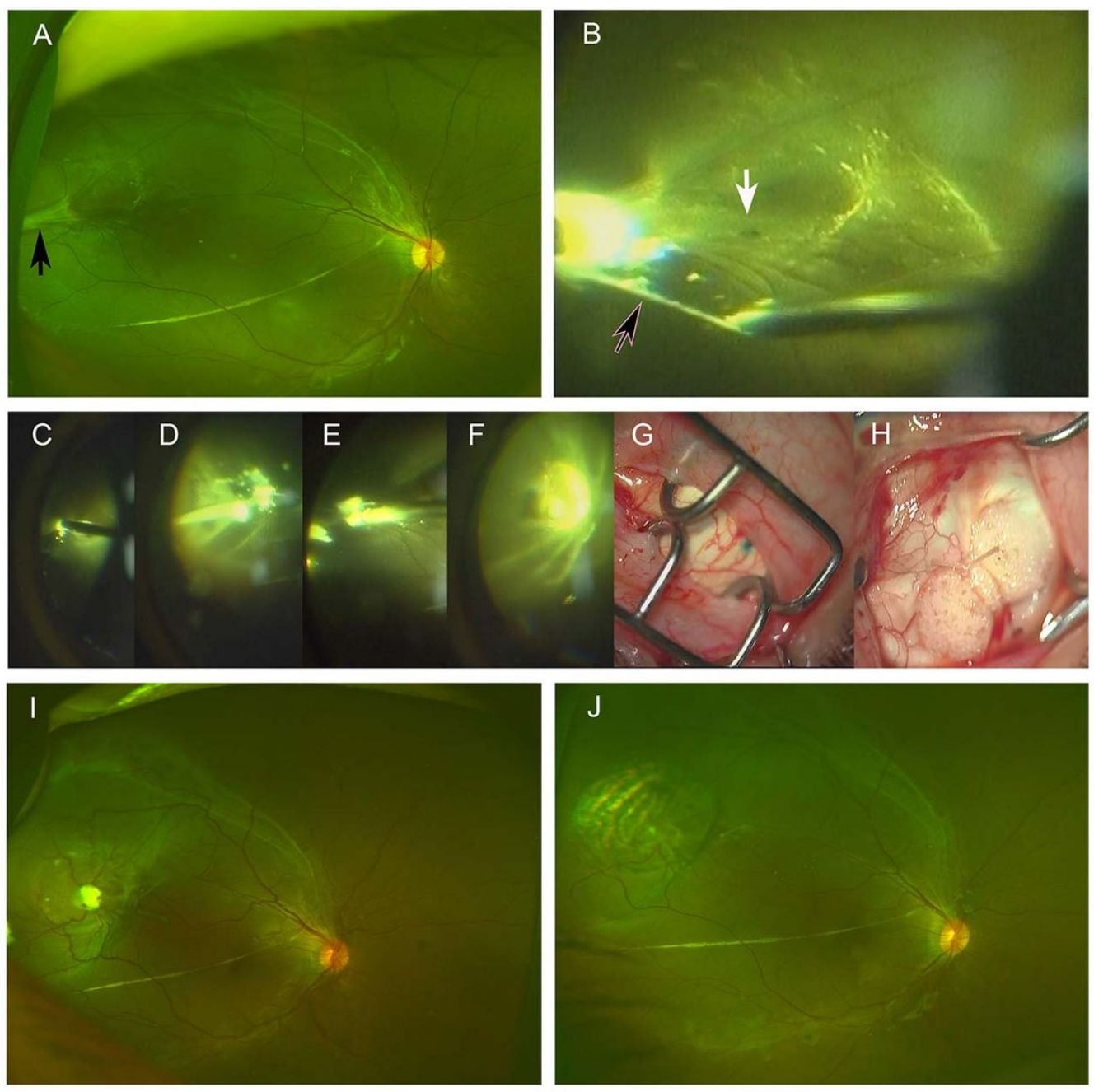

\section{Figure 1}

Case 1, a 7-year-old boy was diagnosed as PHPV and temporal retinal detachment. (A) Preoperative fundus photo. Black arrow shows the vitreous traction; (B) Small retinal hole was found beneath the vitreous traction under the microscopy; $\mathrm{C}-\mathrm{H}$ shows the key steps of the surgical procedures. (C) Coagulation of the vitreous traction; (D) Cut the vitreous traction; (E) Trim the traction by vitrectomy cutter; (F) Cryocoagulation under directly viewing under microscopy; (G) and $(\mathrm{H})$ Minimal invasive conjunctival incision and silicone scleral buckle; $(\mathrm{I})$ and $(\mathrm{H})$ Retinal reattachment with temporal ridge of right eye 2 days and 1 month postoperatively. 

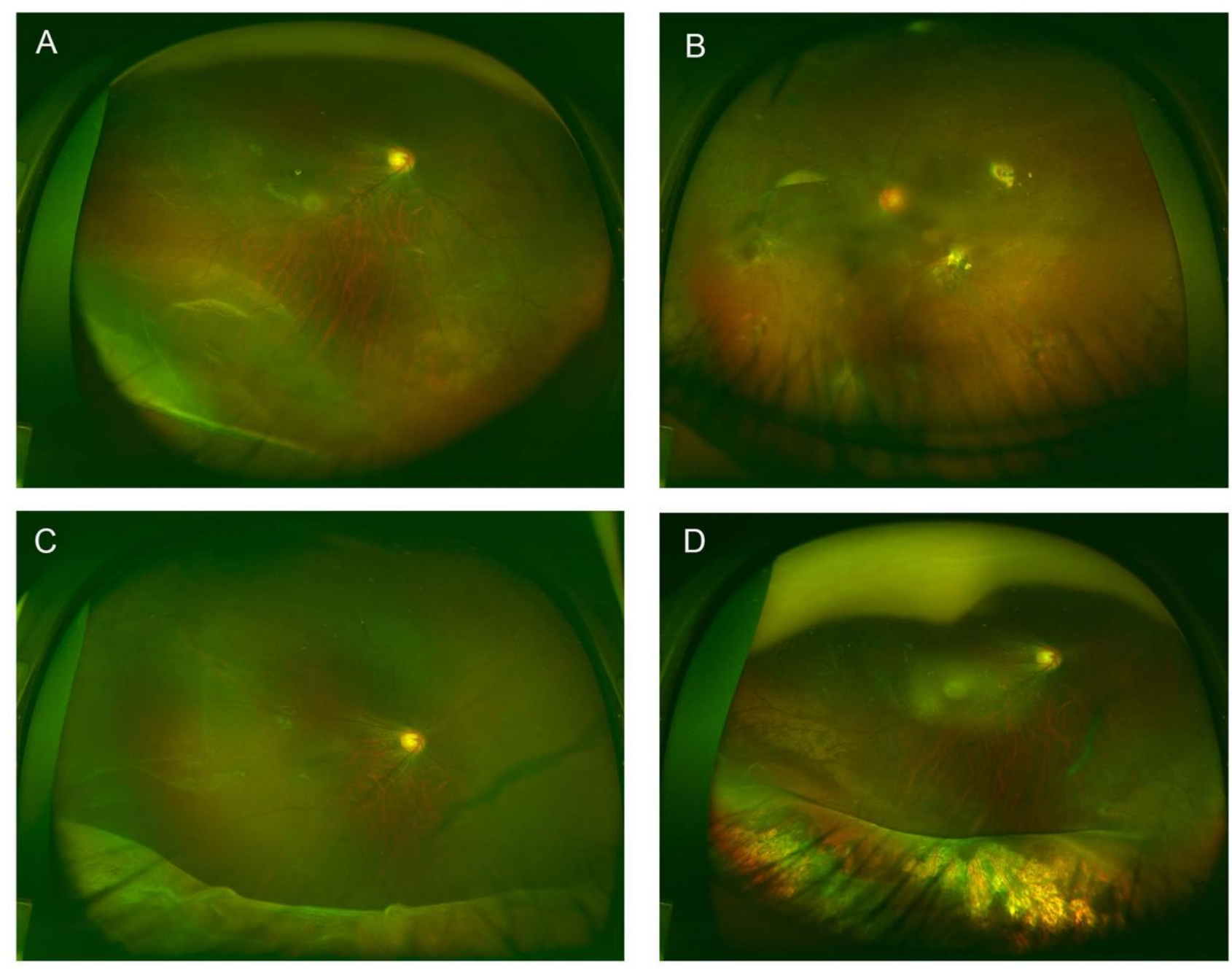

\section{Figure 2}

Case 3, a 13-year-old boy was diagnosed as retinal dialysis of his right eye. He had a history of vitrectomy of his left eye due to retinal detachment. (A) Retinal dialysis of right eye with vitreous traction around the dialysis of ora serrata. (B) Fundus of left eye with silicone oil tamponade. (C) and (D) Retinal reattachment of right eye with inferior ridge 3 weeks and 3 months later after combined local dry vitrectomy and minimally scleral buckling. 

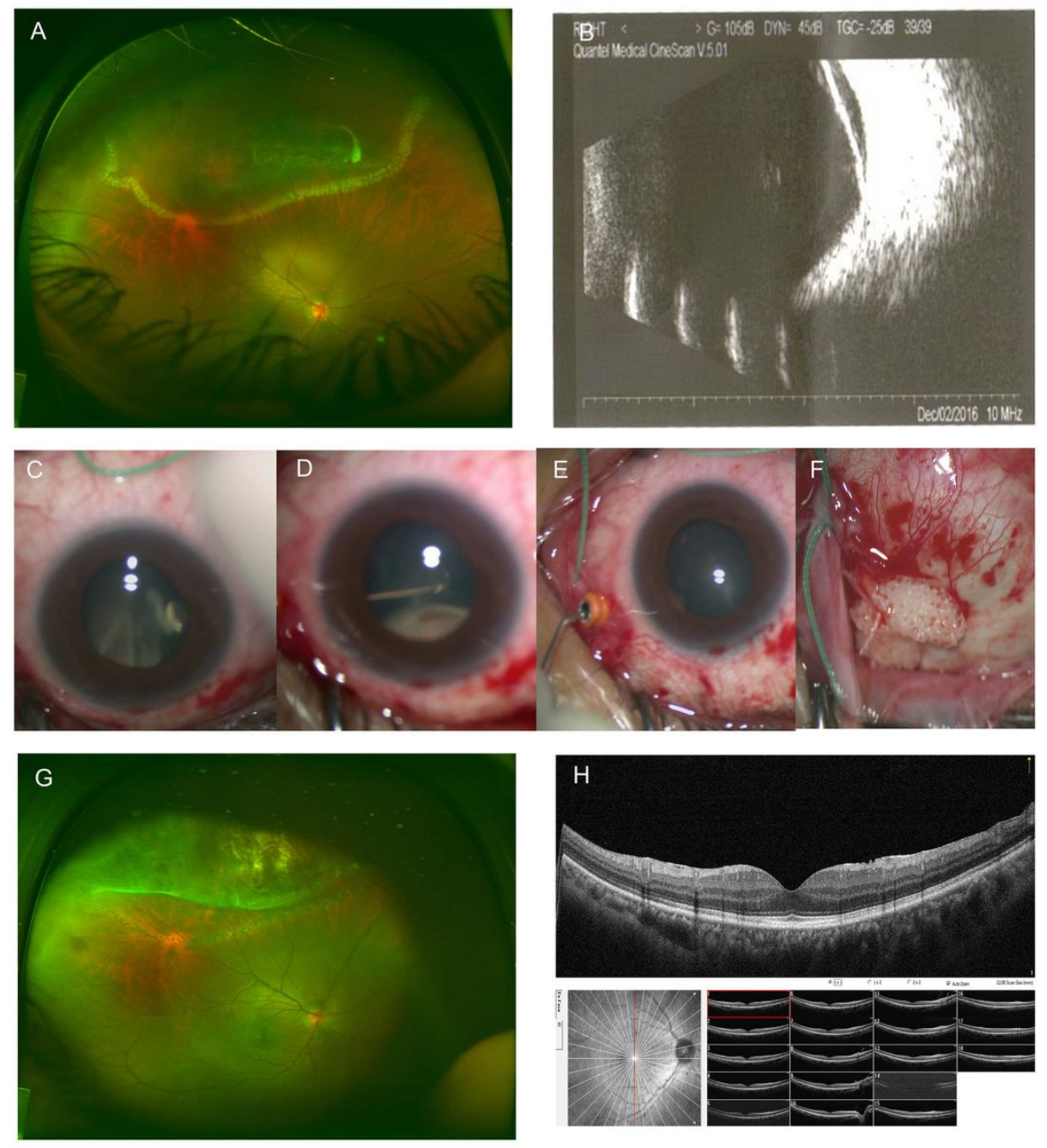

\section{Figure 3}

Case 4, a 45-year-old women was diagnosed as superior retinal detachment of right eye and high myopia of both eyes. She has a history of retinal photocoagulation of the right eye. (A) Preoperative fundus photo shows retinal detachment with retinal holes and vitreous traction. Laser spot can be seen around the posterior margin of the retinal detachment area; (B) B scan of right eye preoperatively; (C) Postoperative fundus photo; (D) Postoperative OCT shows normal macula. E-H shows the key steps of the surgical procedures. (E) and (D) trim the vitreous traction around the retinal holes by vitrectomy cutter. $(G)$ inject the viscoelastic solution into the vitreous cavity to maintain the ocular pressure. $(H)$ Minimal invasive conjunctival incision and silicone scleral buckle. $(\mathrm{I})$ and $(\mathrm{H})$ Retinal reattachment with temporal ridge of right eye 2 days and 1 month postoperatively.

\section{Supplementary Files}

This is a list of supplementary files associated with this preprint. Click to download.

- case2short.mp4

- case1.MP4

- case1.MP4

- case2short.mp4 